\title{
An Active Postvention Program
}

\author{
Frank R. Campbell, Louis Cataldie, John McIntosh, and Kari Millet
}

Baton Rouge Crisis Intervention Center, Baton Rouge, LA, USA

\begin{abstract}
Summary: The Active Postvention Model (APM) described in this article demonstrates how survivors of suicide can be an installation of hope for the newly bereaved and an effective zeferral resource for support in the grief process. The benefit of active postvention compared to passive postvention results in a dracinatic redaction in the elapsed time between death and seeking belp for the survivors who receive the active postvention. Other benefits of the APM are discussed as well.
\end{abstract}

Keywards: Active Postvention Model (APM), strvivors of suicide, suicide, first regponders

Postvention, a term coined by Shneidman (1972), is used to describe "appropriate and helpful acts that come after a dire event." Postvention services have historically been delivered via a passive model, requiring survivors of the suicide death of a loved one to learn about the available resources in some indirect way and often by sheer chance (Campbell, 1997).

A pilot program of the Baton Rouge Crisis Intervention Center (BRCIC) is changing the "stumble factor" for survivors of suicide in Baton Rouge, Louisiana, by replacing the passive model with an active postvention model (APM). Specifically, this APM is known as the Local Outreach to Suicide Survivors Program (LOSS).

\section{The LOSS Program}

The LOSS Program includes a first-response team (The LOSS team) in East Baton Rouge Parish (county) with the purpose of delivering immediate services to survivors of suicide at the time of death. The LOSS team reaches out to survivors to let them know that they are not alone, provides immediate contact and support, informs them of the resources available to them in the community, and provides an installation of hope that they, too, can survive this traumatic loss. The LOSS team is comprised of staff members of the crisis center and para-professional survivor volunteers. All LOSS team members have had additional training to aid them in responding to the scenes of suicide, including crime scene procedures, precautions for exposure to bloodbom pathogens, and supportive counseling training. The team members work closely with the office of Dr. Louis Cataldie, the Coroner of East Baton Rouge Parish, who makes the decision to activate the team to respond to the scene of a suicide.
The LOSS Program is a unique concept that differs in several significant ways from other outreach services for survivors of suicide. First, the LOSS team actually goes to the scenes of suicides to begin helping the survivors as close to the time of death or notification as possible, thereby abolishing the "stumble factor." Team members can provide access to available resources at the scene and begin the grieving-support process. Second, the LOSS team relies heavily on the experiences of the para-professional survivor volunteers, who act as the primary resource at the scenes. By having survivor volunteers at the scene an immediate and valuable bond is established between the newly bereaved and the para-professional survivor team members. This bond simultaneously provides the beginning of an honest conversation about grief after a suicide and the installation of hope. Third, the relationship between the LOSS team and the other first responders (i.e., law enforcement, emergency services, fure department, funeral home representatives, etc.) frequently permits the newly bereaved to have choices which those survivors without an advocate might be denied. Finally, the active model of postvention provides referrals for additional support to all of the individuals at the scene. The friends, neighbors, coworkers and "distant" family members often find themselves overlooked, yet they are oftentimes just as significantly impacted by the death as members of the immediate family.

The value of the LOSS team can be measured by more than the assistance provided to survivors. The team has become a welcomed, and consistently requested, addition to the first responders at the tragic scenes of suicide, or joining law enforcement for a death notification to family members when the next of kin is not at the scene. This has resulted in a sensitization of the other first-responders to the needs of survivors and has reduced the inappropriate attitudes routinely expressed at the scene under the passive 
model. The atmosphere at the scene has changed to a more concerned and caring environment for the survivors (Campbell, 2000) as a result of the sensitizing of the first responders. In the beginning it was common for the law enforcement responders to seem distant and unconcerned, and sometimes inappropriate to the survivors, by remarks made to, and away from, those most impacted by the death. This has been reduced to the point that it is rare to go to a scene and have any negative comments being made about the deceased or the cause of death. First responders had been subjected to these scenes in the past without any backup for their own well-being, and now they are being supported and offered someone to vent to about what they see and feel as well. Because they see first hand the benefits to the survivors, they are more empowered to call for the LOSS team and have often inquired when such a team will be available for other traumatic losses as well.

\section{The Coroner's Perspective}

An essential ingredient for successful implementation of a LOSS team is acceptance, or "buy in," by the various police departments within the jurisdiction of the program's geographical boundaries. In short, if the police don't support LOSS at the hormicide detective level, it will not work. One of the keys to obtaining this acceptance is the perception of LOSS bringing value to the investigation.

In order to build such a foundation of value, endorsement by the coroner can be viewed as the comerstone for implementation. The coroner's role in LOSS is to train the LOSS members on crime-scene etiquette and to act as advocate and emissary of the program. Other training by the coroner is in the area of universal precautions against blood-born pathogens. Crime-scene etiquette involves not only understanding such concepts as evidence, witness handling, and crime scene contamination but also of the protocols for homicide investigation and the goals of the homicide detectives. A suicide is a homicide until proven otherwise and family members often head the suspect list. This, of course, tends to result in more anxiety for the survivors and may become one of the first issues addressed by the LOSS team members.

In the Baton Rouge community, the initial implementation of the LOSS team was viewed with some skepticism by police officers. Their concerns centered on crime scene and witness contamination issues. Initially, detectives questioned "who was LOSS" to come into their crime scene. Over a period of several months, detectives actually began to ask the coroner when those LOSS team folks would be arriving to help with the situation.

The LOSS helps with notification of next-of-kin. The last thing anyone wants is for a suicide to precipitate another suicide and LOSS is viewed as a mechanism to decrease risk of additional suicides. LOSS helps with "hysterical" family members who might otherwise end up being arrested or at least confined to the back of a police unit. Police officers have families also, and they are not strangers to suicide; indeed some are survivors and some are at high risk themselves. On more than one occasion the coroner has reported seeing LOSS team members, at the scene, being engaged by officers who ask questions of the team for personal reasons and even share the information of being survivors themselves. The officers see the benefit of the program and have accepted it. However, homicide detectives now have expectations, which must be met. The team members must show up in a timely manner and continue to be assets and conduct themselves in a professional and knowledgeable manner. If the LOSS team fails to fulfill this role consistently, they will lose the high level of esteem they currently hold with the police as well as the coroner. In this work, $99 \%$ is a failing grade! Therefore, being reliable and predictable in the eyes of law enforcement is essential. You will not get a second chance to leave detectives standing around a crime/suicide scene waiting for the LOSS team that does not show up or cannot be contacted in a reasonable and timely manner.

\section{Contacts: The Outreach}

The active postvention model has received local, national, and international attention, and is the focus of a Discovery Channel documentary entitled "Survivors of Suicide: Those Left Behind," narrated by actress and survivor Mariette Hartley, which is due to be aired in 2004. The success of this award-winning program is rooted in the strong commitment of the team. From January of 1999 through December of 2002 the LOSS team members responded to 93 suicide scenes where they spent 565 hours assisting 1165 survivors. In addition, LOSS team members have provided 86,973 volunteer hours of on-call time. Many of the LOSS team members attend funeral services, help law enforcement with death notifications, conduct intakes and family postvention sessions at the sponsoring crisis center, and serve as peer-facilitators of the weekly Survivors of Suicide Support Group.

\section{The Research Component}

The program contains a research component, approved by the Louisiana State University's IRB, specifically designed to monitor each team member's risk as a result of exposure to the traumatic environment of a suicide scene. The results of this are published elsewhere.

The data of this ongoing investigation into the longrange impact of involvement in this program shows that the depression, anxiety, and bereavement scores for team members are consistently lower than those of the comparison group. In fact, team member's scores have decreased 
throughout the study, suggesting that involvement in the LOSS Program could have a positive psychological benefit for the survivor volunteers. Team members routinely report how much they value the feeling they receive by giving others what they wish they could have received at the time of the death of their loved one.

\section{Conclusions}

Recent developments in suicide awareness and prevention indicate that in spite of the many barriers placed before them, survivors are finding their voices and changing our knowledge about suicide, and altering the stereotypes that have been prevalent throughout the ages. The LOSS team is the most recent development in the effort to help suicide survivors continue this important progression. The first step toward survivor advocacy is survivor healing. Before the formation of the LOSS Program, the average amount of time that passed before a survivor came to the Baton Rouge Crisis Intervention Center for services was $1,742.5$ days (about 4.5 years). The 4 year average for the APM is 39 days after the death. The passive model continues to generate referrals, however the 4-year average is still over 880 days. Postvention can be an important tool for social change, and the LOSS Program is proving to be a useful tool for postvention.

It was Shneidman's contention that "the largest public health problem is neither the prevention of suicide nor the management of suicide attempts, but the alleviation of the effects of stress in the survivors whose lives are forever altered" (1972, p. xi). Perhaps the deployment of an APM like the LOSS team could finally address the challenge set by Shneidman more than 30 years ago.

\section{References}

Campbell FR. Changing the legacy of suicide. Suicide and LifeThreatening Behavior 1997; 27(4).

Campbell FR. Suicide: An American form of abuse. New Global Development (XVI), 2000.

Shneidman ES. Foreword. In AC Cain (Ed.), Survivors of suicide (pp. ix-xi). Springfield, IL: Charles C. Thomas, 1972.

About the authors:

Frank R. Campbell, $\mathrm{PhD}, \mathrm{LCSW}$, is Executive Director of the Baton Rouge Crisis Intervention Center. He is a Past President of the American Association of Suicidology (AAS) and recipient of the AAS's Roger J. Tiemey Award for Service. Louis Cataldie, $\mathrm{MD}$, is Coroner for East Baton Rouge, Louisiana. John McIntosh, $\mathrm{PhD}$, is Chair of the Department of Psychology at Indiana University South Bend, Indiana, past President of the American Association of Suicidology, and recipient of the AAS's Roger J. Tiemey Award for Service. He is widely published and recognized for his work in Suicidology. Kari Millet is the former coordinator of Survivors' Services, ASIST training, and the LOSS program for the Baton Rouge Crisis Intervention Center

Address for correspondence:

Frank R Campbell, PhD, LCSW

Baton Rouge Crisis Intervention Center, Inc 4837 Revere Ave.

Baton Rouge, LA 70808

USA

Tel. +1225 924-1431 (voicemail ext. 12)

Fax $+1225924-6964$

E-mail frankcampbell@brcic.org 